\section{(6) OPEN ACCESS}

\title{
At-risk children with asthma (ARC): a systematic review
}

\author{
Audrey Buelo, ${ }^{1}$ Susannah McLean, ${ }^{1}$ Steven Julious, ${ }^{2}$ Javier Flores-Kim, ${ }^{1}$ Andy Bush, ${ }^{3}$ \\ John Henderson, ${ }^{4}$ James Y Paton, ${ }^{5}$ Aziz Sheikh, ${ }^{1}$ Michael Shields, ${ }^{6}$ Hilary Pinnock, ${ }^{1}$ the \\ ARC Group
}

\begin{abstract}
- Additional material is published online only. To view please visit the journal online (http://dx.doi.org/10.1136/ thoraxjnl-2017-210939)
\end{abstract}

${ }^{1}$ Asthma UK Centre for Applied Research, Usher Institute of Population Health Sciences and Informatics, The University of

Edinburgh, Edinburgh, UK

${ }^{2}$ Medical Statistics Group,

ScHARR, University of Sheffield, Sheffield, UK

${ }^{3}$ Department of Paediatric

Respiratory Medicine, Imperial

College and Royal Brompton

Hospital, London, UK

${ }^{4}$ Department of Population

Health Sciences, Bristol Medical

School, University of Bristol,

Bristol, UK

${ }^{5}$ School of Medicine, College of Medical, Veterinary, and Life

Sciences, University of Glasgow, Glasgow, UK

${ }^{6}$ Centre for Experimental

Medicine, Queen's University,

Belfast, UK

\section{Correspondence to}

Dr Hilary Pinnock, Asthma UK

Centre for Applied Research,

Usher Institute of Population

Health Sciences and Informatics,

The University of Edinburgh,

Edinburgh EH8 9AG, Scotland;

hilary.pinnock@ed.ac.uk

Received 22 August 2017

Revised 12 April 2018

Accepted 16 April 2018

Published Online First

5 June 2018

\section{ABSTRACT}

Introduction Asthma attacks are responsible for considerable morbidity and may be fatal. We aimed to identify and weight risk factors for asthma attacks in children (5-12 years) in order to inform and prioritise care.

Methods We systematically searched six databases (May 2016; updated with forward citations January 2017) with no language/date restrictions. Two reviewers independently selected studies for inclusion, assessed study quality and extracted data. Heterogeneity precluded meta-analysis. Weighting was undertaken by an Expert Panel who independently assessed each variable for degree of risk and confidence in the assessment (based on study quality and size, effect sizes, biological plausibility and consistency of results) and then achieved consensus by discussion. Assessments were finally presented, discussed and agreed at a multidisciplinary workshop.

Results From 16109 records, we included 68 papers (28 cohort; 4 case-control; 36 cross-sectional studies). Previous asthma attacks were associated with greatly increased risk of attack (ORs between 2.0 and 4.1). Persistent symptoms (ORs between 1.4 and 7.8) and poor access to care (ORs between 1.2 and 2.3) were associated with moderately/greatly increased risk. A moderately increased risk was associated with suboptimal drug regimen, comorbid atopic/allergic disease, African-American ethnicity (USA), poverty and vitamin D deficiency. Environmental tobacco smoke exposure, younger age, obesity and low parental education were associated with slightly increased risk. Discussion Assessment of the clinical and demographic features identified in this review may help clinicians to focus risk reduction management on the high-risk child. Population level factors may be used by health service planners and policymakers to target healthcare initiatives.

Trial registration number CRD42016037464.

\section{INTRODUCTION}

Asthma is the most common long-term condition in children, with European prevalence rates among 6-7 year-olds ranging from 5\% in Albania to 21\% in the UK. ${ }^{1}$ Asthma is responsible for substantial morbidity, resulting in 2.8 million school days lost annually in the UK, ${ }^{2}$ many involving time off work for parents/carers. ${ }^{3}$ In the UK, more than 25000 children are admitted annually with an asthma attack. ${ }^{4}$ Frequent attacks affect the quality of life

\section{Key messages}

What is the key question?

- What are the factors that could enable clinicians and healthcare services to 'spot the child' (5-12 years) with asthma who is at increased risk of a severe asthma attack (requiring systemic steroids or hospital care)?

What is the bottom line?

- The 'at-risk' picture that emerges is of a child with persistent symptoms who has had previous attacks and is on a suboptimal treatment regimen, especially if they have poor access to healthcare services or other risk factors including comorbid atopic/allergic diseases, vitamin D deficiency, living in poverty and being of African-American ethnicity.

Why read on?

- This systematic review identifies risk factors and, based on the consensus view of an Expert Panel, weights the factors to enable parents, clinicians and healthcare services to target evidence-based management on children with asthma at most risk of having a severe attack.

of children and their parents, are associated with accelerated loss of lung function ${ }^{5}$ and may be fatal.

Asthma guidelines recommend that monitoring should include regular assessment both of current symptom control and future risk of an attack. ${ }^{67}$ Objective assessment of symptoms may be achieved with questionnaires validated in children (eg, Paediatric Asthma Control Questionnaire ${ }^{8}$; Childhood Asthma Control Test ${ }^{9}$ ) or morbidity scores (eg, Royal College of Physicians three questions ${ }^{10}$ ) but no evidence-based tools exist for informing assessment of future risk in children.

Guidelines list factors associated with an increased risk of attacks, ${ }^{6}$ including a recent history of severe attacks, poor symptom control, allergic sensitisation, comorbid rhinitis, exposure to environmental tobacco smoke (ETS), high use of reliever medication, poor adherence to controller medication, obesity, eosinophilia, elevated $\mathrm{FE}_{\mathrm{NO}}$, psychosocial problems and impaired spirometry. The relative contribution of these factors to increased risk, and how they may be used to stratify

To cite: Buelo A, McLean S Tous S, et al. Thorax 
risk is not clear; clarifying this issue has been identified as a research priority. ${ }^{7}$

We were commissioned by Asthma UK to undertake a systematic review to identify factors associated with the risk of attacks in children aged 5-12 years with asthma and, based on the consensus view of a multidisciplinary Expert Panel, to weight their importance and the strength of the underpinning evidence to inform risk stratification.

\section{METHODS}

The systematic review is registered with PROSPERO (CRD42016037464); the protocol is published. ${ }^{11}$ We followed Cochrane methodology ${ }^{12}$ and Preferred Reporting Items for Systematic Reviews and Meta-Analyses (PRISMA) reporting standards. ${ }^{13}$

\section{Search strategy}

We searched MEDLINE, EMBASE, CINAHL, AMED, PsycINFO and CENTRAL in May 2016: with no language or date restrictions, identified unpublished and in-progress studies from ClinicalTrials.gov and the ISRCTN registry (https://www. isrctn.com), undertook forward and backward citation checks. The search strategy was structured to include terms for 'Asthma' and 'Exacerbations/Attacks' and 'Risk factors/Predictors'. ${ }^{11}$ (Online supplementary table S1 gives detailed search strategies.) We contacted experts in the field for potentially relevant papers and anticipated risk factors to ensure we captured all likely predictors.

\section{Selection of studies}

After initial deduplication and sift of obviously irrelevant titles (NT, SM, SMcL, AudB), two reviewers (NT, SM or AudB and SMcL or HP) independently screened titles/abstracts of papers identified. Two reviewers (AudB and SMcL) screened the full text of potentially eligible studies against review criteria. At each stage, disagreements were resolved by team discussion with advice from the study Steering Group (the grant holders and other members of the ARC group).

\section{Inclusion and exclusion criteria}

The focus of the review was to identify factors that increased a child's propensity to asthma attacks. Definitions ${ }^{6714}$ and key decisions regarding operationalising the inclusion/exclusion criteria are detailed in table 1 . We used the American Thoracic Society/European Respiratory Society Task Force ${ }^{14}$ definition of severe asthma attacks: asthma symptoms and/or airway obstruction outside the normal variation for the patient necessitating a short course of oral corticosteroids and/or hospitalisation/emergency department use. The population included were children aged 5-12 years with a doctor diagnosis of asthma. Studies with a wider range of ages (eg, 3-18 years) were included if children aged 5-12 were reported separately or if more than $50 \%$ of the children were within this age range.

\section{Quality assessment}

We assessed study quality using Newcastle-Ottawa Scale for cohort, case-control and cross-sectional study designs. ${ }^{15}$

Table 1 Criteria for the search strategy and rules devised to operationalise inclusion/exclusion criteria

\begin{tabular}{|c|c|}
\hline Search strategy & Definition \\
\hline $\begin{array}{l}\text { Population } \\
\text { 'Asthma' }\end{array}$ & $\begin{array}{l}\text { Children aged } 5-12 \text { years with doctor-diagnosed asthma, across all } \\
\text { severities and degrees of control }\end{array}$ \\
\hline & Any setting \\
\hline $\begin{array}{l}\text { Outcome } \\
\text { 'Exacerbations/Attacks' }\end{array}$ & $\begin{array}{l}\text { Severe asthma attacks as defined by the ATS/ERS Task Force }{ }^{14} \text { : asthma } \\
\text { symptoms and/or objective evidence of obstruction outside the normal } \\
\text { variation for the patient necessitating (A) a short course (at least } \\
3 \text { days) of oral corticosteroids, and/or (B) a hospitalisation or emergency } \\
\text { department visit requiring systemic corticosteroids }\end{array}$ \\
\hline
\end{tabular}

Risk factors/predictors

Any feature of the child, family or social context, clinical history, examination finding or test routinely available in clinical practice which increased the propensity of the child to have an asthma attack

Any routine clinical care (eg, attendance (or not) at routine reviews) and disease-related behaviours (eg, adherence (or not) to preventer medication)

\section{Rules to operationalise}

We included studies with a wider range of ages if results for children aged

$5-12$ years were reported separately or if more than $50 \%$ of the children were within this age range.

We excluded:

- Studies in which the diagnosis of asthma was not doctor diagnosed (eg parent reported).

- Epidemiological studies in which the denominator was the general population (eg, asthma admissions from deprived/rural/urban communities) as opposed to a population of children with asthma.

We excluded studies assessing risk factors for:

- Attacks defined only by use of rescue bronchodilator medication.

- Poor control/severe asthma (eg, as defined in GINA ${ }^{6}$ ) unless 'attacks' were listed as a separate outcome.

- Failure to recover, relapse, early readmission from an existing attack.

- Fatality/intubation/ICU as specific outcomes (though these may be included within the definition of severe asthma).

We excluded:

- Tests currently only available in the context of research (eg, novel biomarkers, genomics).

- Triggers for attacks, for example, respiratory tract infections, exposure to airborne allergens, exercise.

We excluded:

- Trials of interventions (eg, inhaled steroids, self-management) proven to reduce exacerbations because we anticipated confounding by indication.

- Complex/multifaceted interventions (eg, enrolled in a local disease management initiative) because the impact is unlikely to be generalisable.

We included controlled trials if they included an analysis that provided an estimate of risk of an attack (eg, cohort or cross-sectional studies from baseline data).
Study designs

Cohort, case-control studies and cross-sectional studies (but not case studies and case series) 


\section{Data extraction}

We extracted details of study design, setting, population, methods, risk factors, definition of asthma and attacks, quality assessment, statistical analyses and results relevant to our objectives using a piloted form, modified from the Cochrane Effective Practice and Organisation of Care data collection form. ${ }^{16} \mathrm{We}$ contacted authors to clarify unclear or missing data.

Quality assessment and data extraction were conducted by AudB or SMcL and one of eight reviewers (JFK, MW, HB, VD, SS, MP, HKZ or ED) trained to undertake independent duplicate quality assessment and data extraction. Disagreements in quality assessment were independently verified and arbitrated by the principal investigator (HP) who also checked the data presented in the tables.

The results for each risk factor were entered onto a table (online supplementary table S2), in order to facilitate weighting. Within each factor, the results were listed from strongest to weakest study design (ie, cohort, case-control, then cross-sectional) and then ranked by study quality (quality assessment score).

\section{Data synthesis: risk factor weighting}

We anticipated that clinical and statistical heterogeneity of data would preclude formal meta-analyses. We therefore convened an Expert Panel (selected to provide a range of perspectives from among senior clinical academics of the Asthma UK Centre for Applied Research and the research team) comprising a general practitioner (GP) (HP), three respiratory paediatricians (JYP, $\mathrm{JH}, \mathrm{MS}$ ) and two researchers with a public health background (AudB, JFK), to make weighting decisions by reviewing the ORs and CIs, or other relevant statistics, as presented for each risk factor in online supplementary table S2. The Panel also had access to the full-text papers. The experts initially worked independently, and then met to reach consensus on weighting. In methodology analogous to the grading of recommendations in which both outcomes and quality of evidence are assessed, there were two decisions to be made:

1. What is the risk associated with each factor? Following discussion, thresholds for the risk weighting based on the majority of ORs for each factor were agreed (see table 2). The risk factor weighting ranged from 'no', 'slightly', 'moderately' or 'greatly' increased risk of future attack.

2. How confident is this estimate of risk? The Expert Panel based the confidence assessment on the following criteria: the number of studies, study design (cohort, case-control and cross-sectional), quality of studies included (NewcastleOttawa Scale), consistency of the results and the biological

Table 2 Thresholds for weighting risk factors

\begin{tabular}{|c|c|c|}
\hline & Description & $\begin{array}{l}\text { Thresholds and criteria for } \\
\text { decision }\end{array}$ \\
\hline \multirow[t]{4}{*}{ Risk weighting (OR) } & Greatly increased risk & Majority of ORs $>2.5$ \\
\hline & Moderately increased risk & Majority of ORs 1.5-2.5 \\
\hline & Slightly increased risk & Majority of ORs 1.1-1.5 \\
\hline & No effect & Majority of ORs <1.1 \\
\hline \multirow[t]{3}{*}{ Confidence } & Highly confident & \multirow{3}{*}{$\begin{array}{l}\text { Number, design and quality of } \\
\text { studies, consistency of results, } \\
\text { biological plausibility of factors }\end{array}$} \\
\hline & Moderately confident & \\
\hline & Slightly confident & \\
\hline Inconclusive & Unable to decide on risk & $\begin{array}{l}\text { Inconsistent or insufficient } \\
\text { evidence }\end{array}$ \\
\hline
\end{tabular}

plausibility of the factors' effect on risk of future attacks to determine the confidence with which the estimates were made. Assessments were rated as 'highly', 'moderately', 'slightly' confident or 'inconclusive/insufficient evidence'.

At the consensus meeting, each factor was considered in turn and all available data taken into account when reaching the decision on risk and confidence. Any subsequent discussion was carried out by email.

\section{Data synthesis: overarching risk}

Risk factors for which there was sufficient evidence to reach a consensus decision on weighting and confidence in the assessment based on the decisions reached during Expert Panel discussion were illustrated on a bubble plot. The position of the bubble denotes the weighting of the risk factor and the size of the bubble indicates confidence in the estimate.

\section{End-of-project workshop}

An end-of-project videoconference (to allow UK-wide participation) workshop was held in January 2017, in which the researchers and the members of the Expert Panel were joined by a multidisciplinary group $(n=18$ : including medical/nursing professionals from primary and secondary care, health service researchers, patient and public involvement (PPI) members) who reviewed and helped interpret the findings. In addition to the weighting table, data on each factor were presented to the workshop as Forest plots (online supplementary table S3) and the bubble plot constructed to visually display the overall results. Each risk factor was discussed, the weighting assessment reviewed and agreed, and the implications considered from the perspective of the different stakeholders.

\section{Patient and public involvement}

Two parents of children with asthma (recruited from the Asthma UK Centre for Applied Research PPI Group) were involved throughout the study. In addition, representatives of Asthma UK attended the end-of-project workshop.

\section{Updating prior to publication}

In order to update the review prior to publication, we undertook forward citation on all included studies (January 2017). Pursuing references from included studies is an efficient approach to updating systematic reviews as it is unlikely that relevant papers will have been published without citing at least one of the included studies. ${ }^{17}$

\section{RESULTS}

\section{Search results}

The searches yielded 21963 records. Figure 1 (PRISMA diagram) gives details of the search and selection process. After deduplication and title/abstracts screening, 209 papers remained for fulltext review of which 45 were included. Forward and backward citations yielded 23 additional papers; thus, 68 studies were included in the final analysis.

\section{Characteristics of studies}

Of the 68 studies, 28 were cohort, ${ }^{18-47} 4$ were case-control ${ }^{48-51}$ and 36 were cross-sectional studies. ${ }^{52-85}$ Study size varied markedly from 38 participants with severe asthma in a study from the Netherlands ${ }^{20}$ to 6.7 million participants in a US census-based study. ${ }^{77}$ The studies came from 10 countries: 53 were based in the USA, 1819 21-2427 28 30-46 49 51-54 57-61 $636566687071737476-78$ 80-84 86 5 in the Netherlands, ${ }^{20} 294748643$ in Puerto Rico, ${ }^{505556} 2$ in 


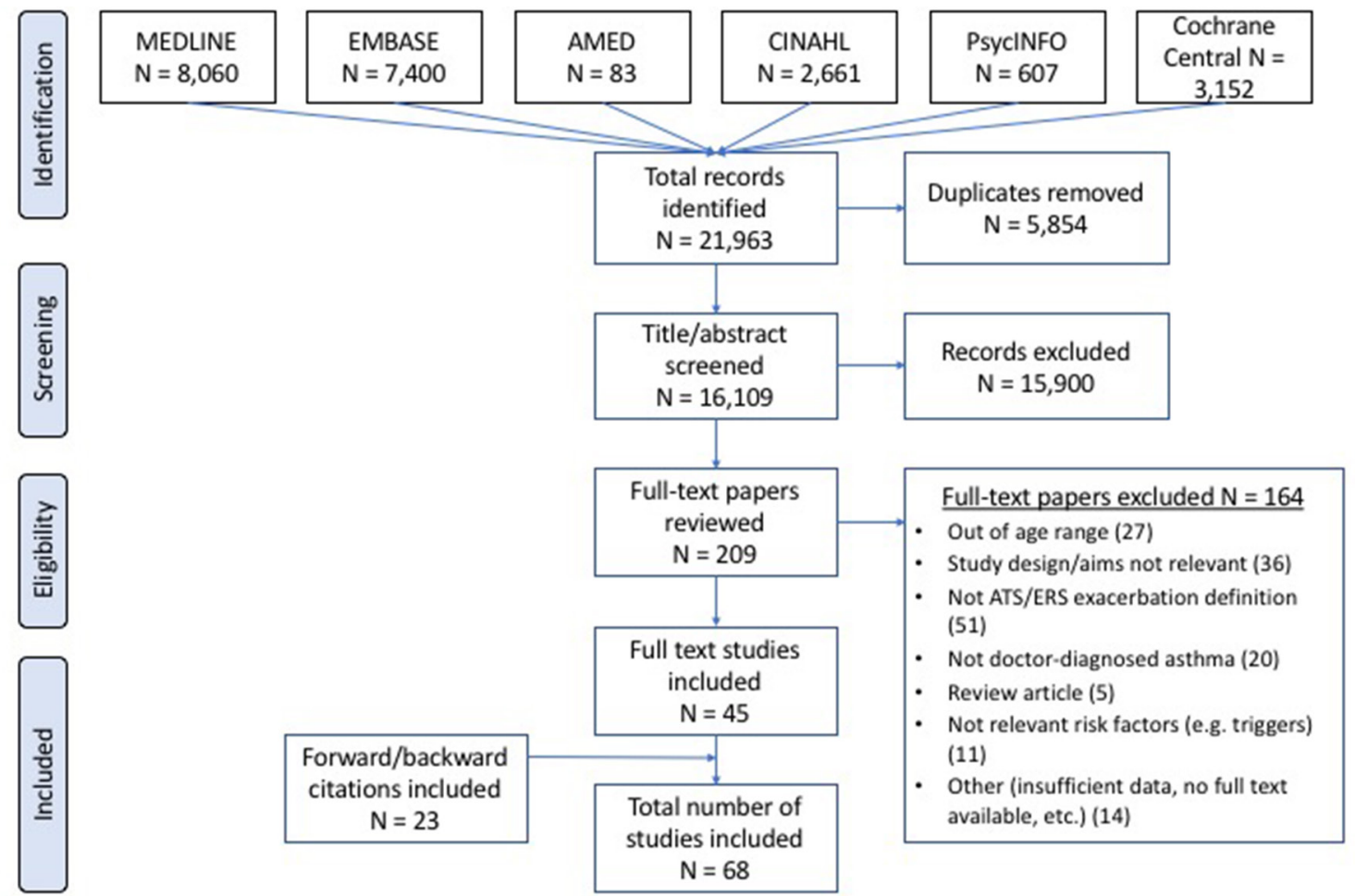

Figure 1 Preferred Reporting Items for Systematic Reviews and Meta-Analyses (PRISMA) flow diagram. ATS, American Thoracic Society; ERS, European Respiratory Society.

Canada, ${ }^{2662}$ and 1 each in Brazil, ${ }^{75}$ Chile, ${ }^{72}$ Costa Rica, ${ }^{69}$ France, ${ }^{67}$ Trinidad $^{79}$ and the UK. ${ }^{25}$ Publication dates ranged from $1993^{74}$ to $2017 .^{18}$

The studies were heterogeneous on most characteristics, including population size, recruitment strategy, definitions of risk factors and attacks, and analytical approaches (confirming our decision that meta-analysis was not appropriate). Figure 2 shows how key variables are illustrated in the Forest plots.

Study quality varied (figures 3-6; online supplementary table S2). Most studies adjusted for at least age and gender, though 10 studies did not report adjusting for any potential confounders, reducing their quality score. ${ }^{28} 45476267798183-85$

\section{Overview of results}

There were 33 risk factors identified, covering asthma disease status, medication use, allergy/atopy, social context, care and services, environment, and demography. Online supplementary table S2 is the full weighting table containing detailed information about populations studied, definitions used and analyses performed grouped by risk factor. Online supplementary table S3 summarises the data for each risk factor (including Forest plots of ORs where there were sufficient data) and the rationale for the weighting decisions. Figures 3-6 summarise the two detailed supplementary tables including simplified Forest plots. The text below synthesises the findings and weighting for each risk factor.

The overarching risk assessment is illustrated in a bubble plot (figure 7).

\section{Greatly or moderately/greatly increased risk of attacks (figure 3)}

Previous attacks $(n=11)$

Previous attacks were consistently associated with a greatly increased risk of future attacks (ORs between 2.0 and 4.1)..$^{25272935-374344698184}$ Due to the consistency of findings and quality of the studies the Panel was highly confident in this assessment (figure 3).

Poor control and/or persistent symptoms $(n=11)$

Ten studies had at least one significant result demonstrating that poor control or persistent symptoms identified a child at moderately/greatly increased risk of future attacks (ORs between 1.4 and 7.8). ${ }^{20273841496265697585}$ The exception was a small $(n=165)$, short duration (3 months) cohort study of moderate quality which showed no association. ${ }^{45}$ The Panel was highly confident in this assessment. Persistent symptoms of any severity

\begin{tabular}{|c|c|c|c|}
\hline Study design & Size: Number of children & Outcome & Decision rules \\
\hline $\begin{array}{l}\text { Cohort } \\
\text { Case-control } \\
\text { Cross-sectional } \\
\text { Quality scores by names of papers }\end{array}$ & $\begin{array}{l}<1,000 \\
1,001-10,000 \\
>10,001\end{array}$ & $\begin{array}{ll} & \text { Combination outcome } \\
& \text { Hospitalisation } \\
& \text { ED visit } \\
\quad \text { Oral steroid (OCS) course } \\
\text { Urgent/unscheduled care }\end{array}$ & $\begin{array}{l}\text { OR }<1.1 \text { no effect, } \\
1.1-1.5 \text { slightly increased risk, } \\
1.5-2.5 \text { moderately increased risk, } \\
>2.5 \text { greatly increased risk } \\
\text { Interpretation based on number, design and } \\
\text { quality of studies, consistency of results, } \\
\text { biological plausibility. }\end{array}$ \\
\hline
\end{tabular}

Figure 2 Key variables and key to Forest plots. ED, emergency department. 


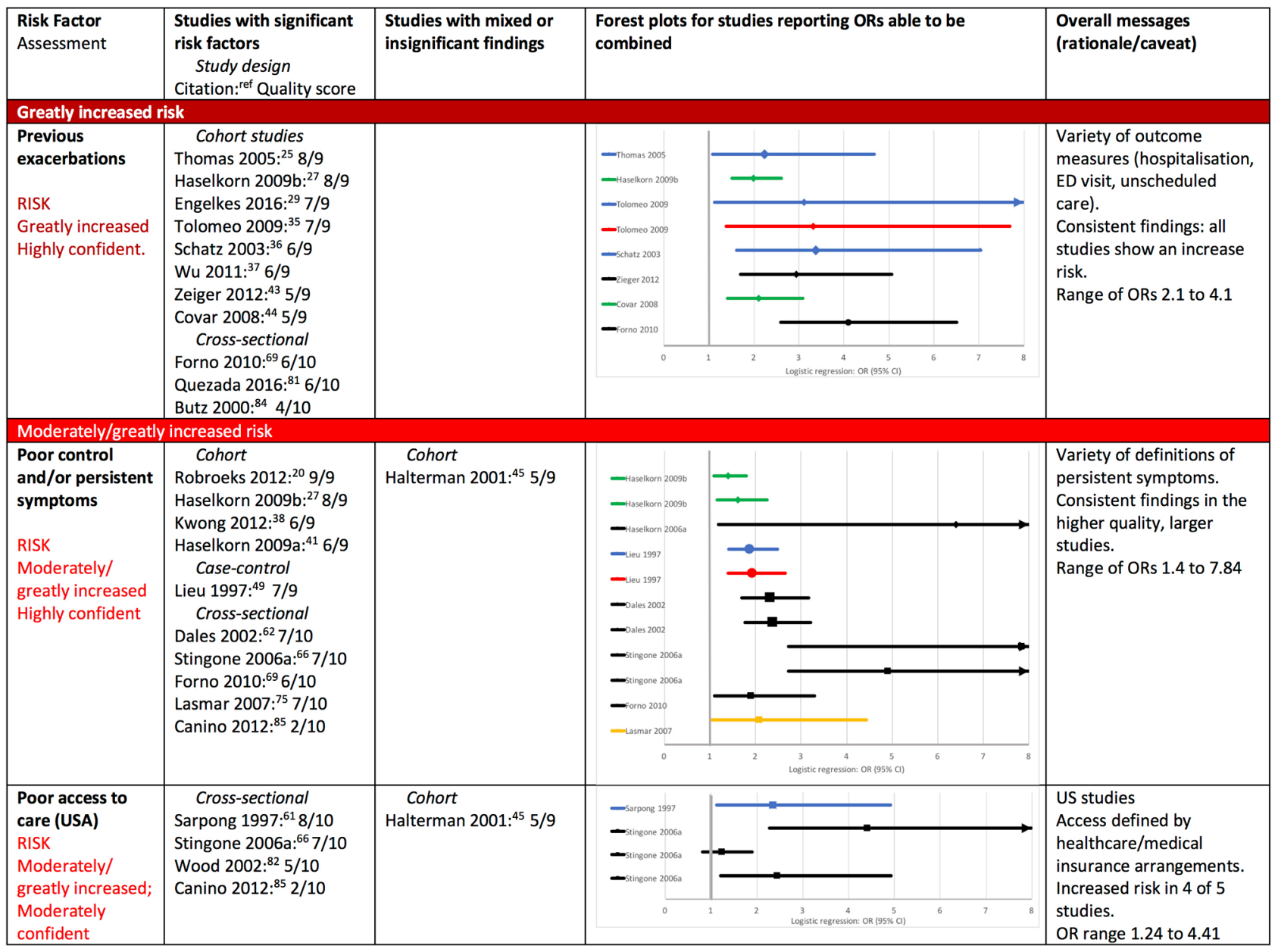

Figure 3 Greatly increased risk: evidence for risk factors and weighting decisions. Note: The scale on all the Forest plots has been curtailed at an OR of 8 to enable comparison between the plots for the different factors. If the Cls are very wide, and the upper limit extends beyond the plot this is indicated with a line with an arrow. (95\% Cls are given in online supplementary table S2 if required.) ED, emergency department.

(as opposed to intermittent symptoms) were associated with greater risk. ${ }^{2738456569}$

\section{Poor access to healthcare $(n=5)$}

Five studies examined access to healthcare defined by insurance status. Four demonstrated that poor access to healthcare was associated with a moderately/greatly increased risk of attacks. ${ }^{61658285}$ A small cohort study of moderate quality demonstrated no increased risk in children with or without Medicaid (a US social welfare programme). ${ }^{45}$ The Panel was moderately confident in this assessment. The studies were all US based with participants from deprived inner-city populations: one study controlled for ethnicity and poverty. ${ }^{65}$

\section{Moderately increased risk of attacks}

Suboptimal drug regimen $(n=9)$

Five of the seven studies that examined high reliever (short-acting beta $_{2}$ agonist (SABA)) use showed a positive association with risk of attacks. 2536434954 The increased risk was judged to be slight (ORs between 1.2 and 1.3 in the three larger studies ${ }^{253649}$ ), though none of the studies assessed very high levels of SABA use (figure 4).

Paradoxically, controller medication use was associated with an increased risk of attacks, as clinicians followed guideline recommendations and prescribed inhaled corticosteroids to children with poor control and previous exacerbations ('confounding by indication'). Sixteen studies were included in this category: nine were suggestive of confounding by indication, 252948505355565981 four demonstrated fewer exacerbations with controller use ${ }^{18353684}$ and three showed no effect. ${ }^{316569}$

The most sensitive marker of moderately increased risk was the ratio of controller-to-total medication. Suboptimal regimens were typically defined (in accordance with Healthcare Effectiveness Data and Information Set criteria ${ }^{86}$ ) as a ratio of the number of prescriptions for controller medication to total number of prescriptions for asthma medication $<0.5$. Six of seven studies that used this marker showed a significant relationship between a suboptimal regimen and asthma attacks (ORs between 1.2 and $2.3^{182426315354}$ ). In other approaches, two large, high-quality cohort studies showed an association with use of regular medication and fewer attacks. ${ }^{23} 29$ Thus, the Panel considered that a suboptimal regimen was associated with moderately increased risk, and were highly confident in their assessment.

\section{Comorbid atopic/allergic diseases $(n=6)$}

Two large, high-quality cohort studies analysed primary care records from the $\mathrm{UK}^{25}$ and the Netherlands. ${ }^{29}$ The UK study found comorbid allergic rhinitis increased the odds of hospitalisation by 2.3 (95\% CI 1.4 to 3.9$),{ }^{25}$ whereas the Netherlands study found no increased risk of attacks in children with comorbid eczema (RR $0.8,95 \%$ CI 0.4 to 1.4 ), allergic rhinitis (RR $0.8,95 \% \mathrm{CI} 0.5$ to 1.2 ) or conjunctivitis (RR $1.4,95 \% \mathrm{CI}$ 0.7 to 2.7 ) compared with no comorbid allergic disease. ${ }^{29}$ 


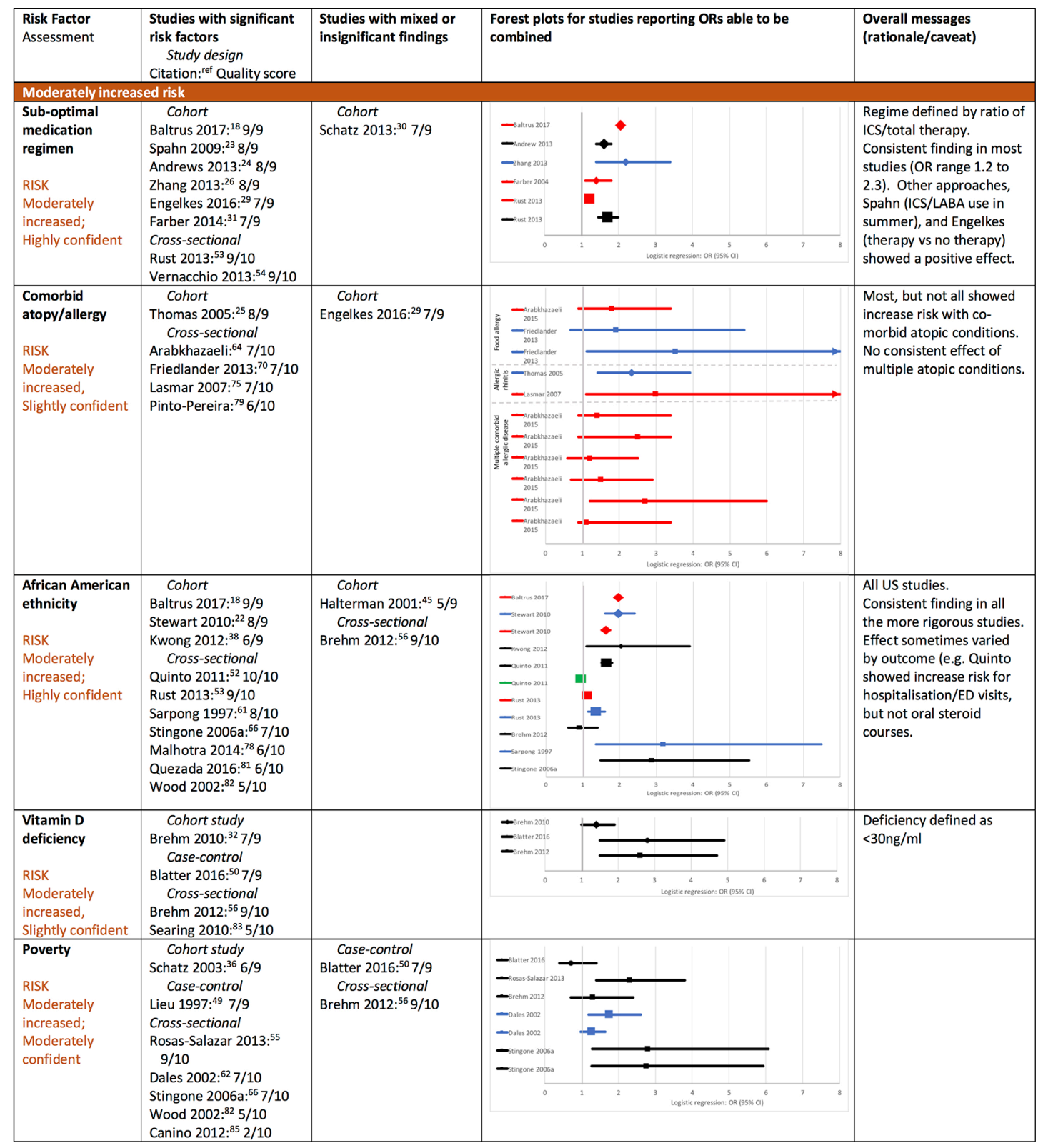

Figure 4 Moderately increased risk: evidence for risk factors and weighting decisions. Note: The scale on all the Forest plots has been curtailed at an OR of 8 to enable comparison between the plots for the different factors. If the Cls are very wide, and the upper limit extends beyond the plot this is indicated with a line with an arrow. (95\% Cls are given in online supplementary table S2 if required.) ED, emergency department; ICS, inhaled corticosteroid; LABA, long-acting $\beta_{2}$ agonist.

The remaining four cross-sectional studies all demonstrated at least one positive association between comorbid atopic/allergic conditions and risk of attacks though CIs were wide. ${ }^{6407579}$ The Panel concluded that that there was a moderately increased risk of attacks with comorbid atopic/allergic disease, but they were only slightly confident in this assessment.

\section{African-American ethnicity $(n=12)$}

Twelve US-based studies examined the association between African-American ethnicity/'race' and the risk of attacks. ${ }^{182238455253566165788182}$ Of the 12 studies, 10 reported at least one significant result demonstrating an increased risk of attacks in African-Americans compared with white or 'non-black'

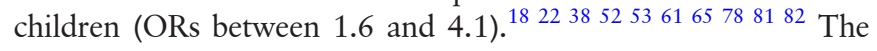
exceptions were a study that assessed the impact of African ancestry in a Puerto Rican population, ${ }^{56}$ and a small cohort study. ${ }^{45}$
Six of these studies demonstrated that the increased risk in African-Americans persisted after controlling for deprivation and/or poverty, ${ }^{6065}$ area of residence, ${ }^{61}$ healthcare provision ${ }^{22} 38536165$ or parental education. ${ }^{52}$ Two studies compared risk in Black and Hispanic populations ${ }^{2252}$ : the risk was considerably less in Hispanic populations. Overall, the Panel was highly confident that African-American ethnicity was associated with moderately increased risk of asthma attacks.

Vitamin D deficiency $(n=4)$

Three small studies showed a significant association between vitamin D insufficiency (vitamin $\mathrm{D}<30 \mathrm{ng} / \mathrm{mL}$ ) and acute attacks (ORs between 2.2 and 2.8), ${ }^{505683}$ though a larger $(\mathrm{n}=1024)$ cohort study found only a borderline effect (OR $1.4,95 \%$ CI 1.0 to 1.9 ). ${ }^{32}$ Thus, the Panel was slightly confident that vitamin D deficiency was associated with a moderately increased risk of attacks. 


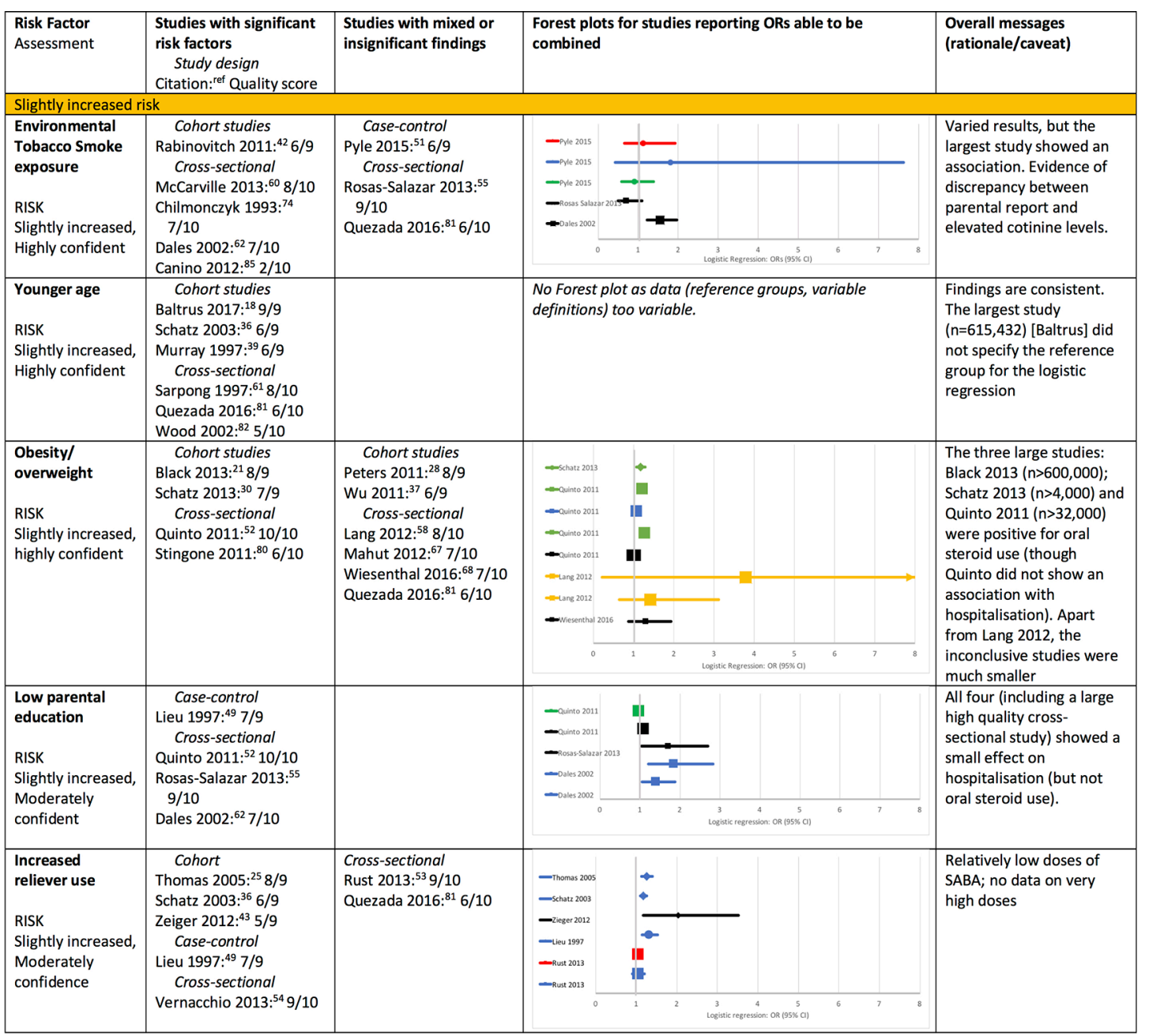

Figure 5 Slightly increased risk: evidence for risk factors and weighting decisions. Note: The scale on all the Forest plots has been curtailed at an OR of 8 to enable comparison between the plots for the different factors. If the Cls are very wide, and the upper limit extends beyond the plot this is indicated with a line with an arrow. (95\% Cls are given in online supplementary table S2 if required.) SABA, short-acting beta, agonist.

Poverty $(\mathrm{n}=9)$

Nine studies examined the effects of poverty (variously defined as annual family income $<$ US\$15 000; <US\$20 000; <US\$40 000 ; receiving benefits) on risk of attacks in children with asthma. Seven studies had at least one positive association between risk of attacks and poverty level (ORs between 1.4 and 2.8). ${ }^{3049} 5562658285$ The exceptions were two small Puerto Rican studies. ${ }^{5056}$ The Panel was moderately confident that poverty moderately increased risk of attacks.

\section{Slightly increased risk of attacks \\ ETS exposure $(\mathrm{n}=8)$}

Five studies found at least one positive association between ETS exposure and asthma attacks. ${ }^{42} 60627485$ One high-quality cross-sectional study highlighted that the association between cotinine levels and risk of attack was lost when parent report was used to estimate ETS. ${ }^{60}$ Of note, the three negative studies relied on parental report. ${ }^{515582}$ The Panel was highly confident that ETS exposure was associated with a slightly increased risk of asthma attack (figure 5).

Younger age $(n=6)$

All six of the studies that examined the effect of age on risk of asthma attacks found that younger children (within the 5-12 age range) were more likely to have an attack. ${ }^{18} 3639618182$ The ORs ranged from 0.8 to 1.0 (indicating slightly decreased risk as age increased); the Panel was highly confident of this.

\section{Overweight/obesity $(n=10)$}

Four studies (including three very large high-quality studies) showed a significant, though small association between overweight or obesity and increased risk of attacks. ${ }^{21} 305280$ The Panel was highly confident that there was a slightly increased risk of an attack in overweight or obese children.

Low parental education $(n=4)$

All four studies, ${ }^{49} 525562$ including one large, high-quality cross-sectional study ${ }^{52}$ showed slightly increased risk of attacks in children of families with low parental education level (ORs between 1.1 and 1.9). The Panel was moderately confident in this assessment.

\section{No effect on risk of attacks}

Gender $(n=14)$

Two studies found girls at an increased risk of attacks, ${ }^{52} 53$ and three found boys at increased risk ${ }^{186065}$; the other nine studies showed no gender difference. ${ }^{29} 3638456162778185$ Thus, the Panel 


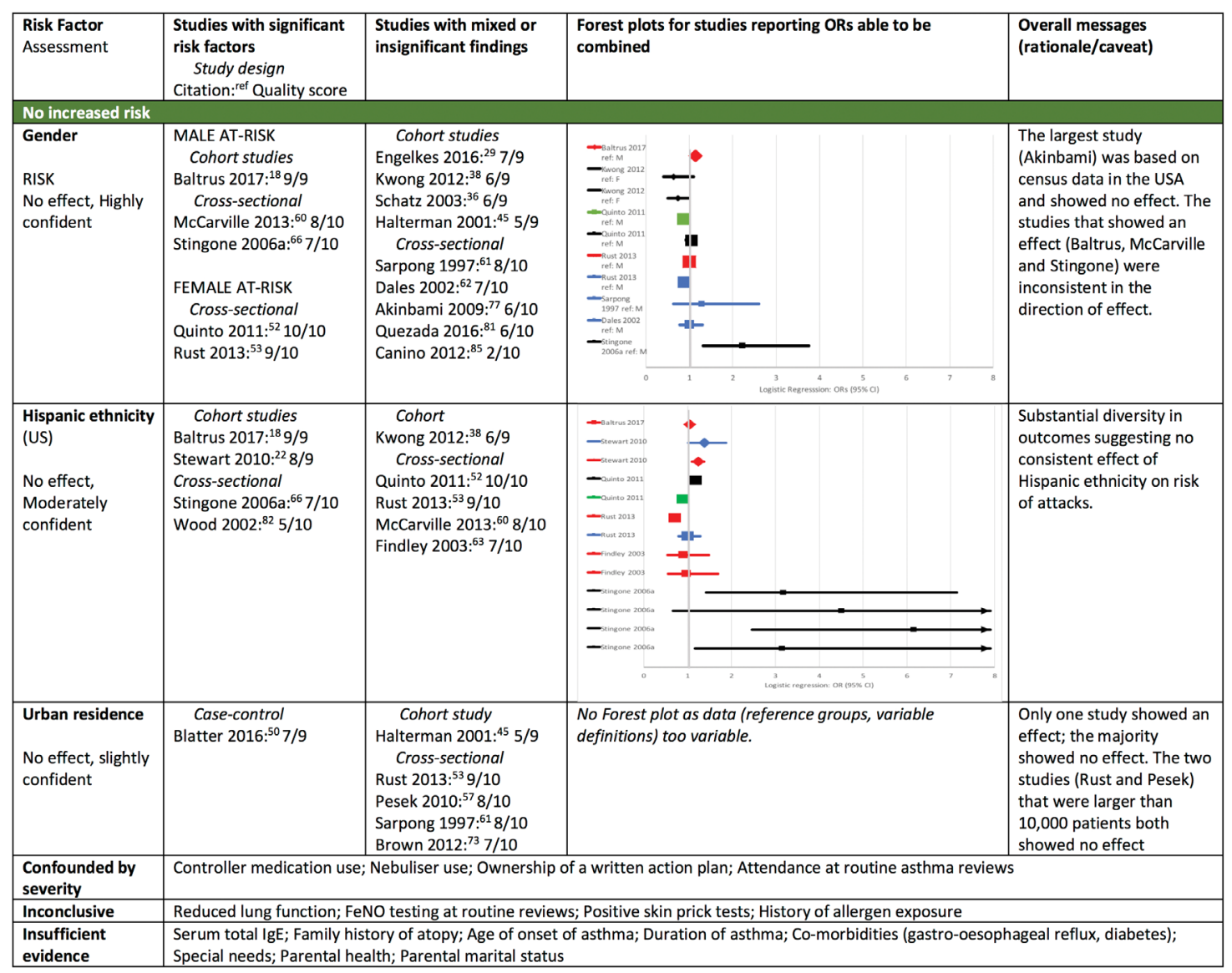

Figure 6 No increased risk, confounded and inconclusive factors: evidence for weighting decision. Note: The scale on all the Forest plots has been curtailed at an OR of 8 to enable comparison between the plots for the different factors. If the Cls are very wide, and the upper limit extends beyond the plot this is indicated with a line with an arrow. (95\% Cls are given in online supplementary table S2 if required).

was highly confident that the child's gender had no effect on risk of attacks (figure 6).

Hispanic population $(n=9)$

Overall, the findings in the US Hispanic population were inconsistent; with the majority of studies demonstrating no increased risk, ${ }^{386063}$ or inconsistent risk across the outcome measures used. $^{52}$ Four studies showed a small increased risk ${ }^{18} 2282$ (one with very wide $\mathrm{CIs}^{65}$ ) and one showed a reduced risk of emergency department visits. ${ }^{53}$ The Panel thus concluded that overall there was no increased risk, but their confidence in this assessment was only moderate.

Urban residence/proximity to major roads $(n=6)$

One case-control study showed a small increased risk of attacks in children living very close to a major road. ${ }^{50}$ The other five studies ${ }^{45} 5376173$ were negative including two large, high-quality cross-sectional studies, which controlled for a broad range of confounders. ${ }^{53} 57$ The Panel was slightly confident in their assessment of no effect.

\section{Confounded by severity}

Controller medication use, nebuliser use, ownership of written asthma action plans and routine asthma reviews were all associated with increased risk of attacks and were considered by the panel to be confounded by severity. (For details see online supplementary tables S2 and S3).

\section{Insufficient evidence to draw a conclusion}

For 12 factors we found inconclusive/insufficient evidence to draw a conclusion. These are listed at the end of figure 6 ; details about why the data were considered to be inconclusive/insufficient are provided in online supplementary table S3, with full description of all the studies in online supplementary table S2.

\section{DISCUSSION}

\section{Main findings}

This systematic review aimed to identify factors which would identify children aged 5-12 years with asthma who are at increased risk of acute attacks. The child who had a history of previous attacks and persistent asthma symptoms was at greatly increased risk of a future attack, especially if they had poor access to care. Other key markers of moderately increased risk were a suboptimal drug regimen, comorbid atopic/allergic disease, African-American ethnicity, poverty and vitamin D deficiency. Younger age, exposure to ETS, being overweight and low parental education were associated with a slightly increased risk, 
Previous attacks

Persistent symptoms

Poor access to care (US)

Sub-optimal ICS/total ratio

Comorbid atopy/allergy

African American race (US)

Vitamin D deficiency

Poverty

ETS exposure

Younger age

Obesity/overweight

Low parental education

Increased SABA use

Gender

Hispanic ethnicity (US)

Urban residence

The assessment of risk is illustrated by the
position of the bubble on the plot

The size of the bubbles indicates the confidence with which the assessment was made.

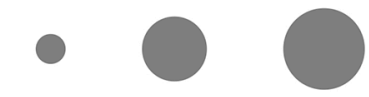

Slightly, Moderately, Highly confident

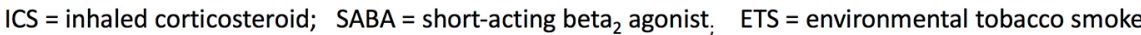

Figure 7 Summary of risk factors and weighting. ETS, environmental tobacco smoke; ICS, inhaled corticosteroid; SABA, short-acting beta 2 agonist.

but gender, urban residence and Hispanic ethnicity were not associated with increased risk.

\section{Strengths and limitations}

Despite our wide-ranging search strategies, we may not have identified all significant risk factors. Nevertheless, we identified papers related to almost all the predictors suggested by guidelines and experts in the field, lending face validity to our findings. The main omissions were that preterm delivery and eosinophilia were suggested, but not investigated as risk factors in any of the studies that we identified. That an additional 23 studies were found during forward and backward citations demonstrates the challenge in developing a comprehensive, but manageable, search strategy in such a broad area. There were some factors about which we found very little evidence and were thus unable to reach a conclusion (eg, comorbidities, parental health, $\mathrm{FE}_{\mathrm{NO}}$ testing); lack of evidence, however, does not mean they are not significant factors. We excluded factors not available in routine clinical practice (eg, novel biomarkers ${ }^{87}$ ) which means that our conclusions are immediately transferable to contemporary clinical practice. The overweight of data from the USA ( $78 \%$ of studies included) limits the generalisability of the evidence for some factors (eg, ethnicity, poverty, access to healthcare) which may not be directly transferrable to other healthcare contexts.

The heterogeneity of the studies in terms of definitions of attacks (hospitalisations, emergency department visits, unscheduled GP care, oral steroids courses), thresholds applied to predictors (eg, definitions of persistent/severe symptoms, income levels associated with poverty, objective or reported assessment of ETS), duration of follow-up, provenance of data (collected for research or routine data) as well as study design and analysis precluded meta-analysis. To reduce potential subjectivity, we adopted a rigorous approach to weighting the factors using an Expert Panel's consensus to define initial weightings and a multidisciplinary end-of-project workshop at which the findings were discussed, refined and agreed. This breadth of internationally recognised professional experience (although all UK based) assisted the interpretation of our findings and lends credibility to our conclusions. 


\section{Implications for parents and clinical practice}

Our findings suggest that it is possible to identify the 'high-risk' child with asthma. The factors associated with moderately or greatly increased risk are easily identifiable in routine practice. For example: a history of acute attacks, persistent troublesome symptoms, frequency of prescription requests and comorbid atopic/allergic conditions are recommended components of regular reviews, ${ }^{6788}$ and knowledge of the social context is a core component of family medicine practice. ${ }^{89} 90$

Identifying that their child is 'at-risk' enables parents to take decisions about modifying risk, such as reducing exposure to ETS, and reconsidering the necessity for controller treatment against their concern about harms of regular medication. ${ }^{91}$ Clinicians alerted to the 'at-risk' child can target care, specifically instituting evidence-based management (regular controllers ${ }^{67}$; supported self-management ${ }^{92}$ ) to reduce risk.

\section{Implications for healthcare systems and policymakers}

Poor access to care and living in poverty were important risk factors that should be targeted by policymakers and health service planners to reduce risk of acute attacks in children living in high-risk populations. At a public health level, strategies for reducing smoking ${ }^{93}$ and targeting the growing epidemic of obesity in children ${ }^{21}$ will also contribute to reducing risk. In the USA, people from African-American communities living in deprived communities are at particular risk.

\section{Implications for future research}

Formal prognostic modelling is needed to validate the risk factors identified in this review, ${ }^{94}$ and future research should assess whether risk assessment based on these factors improves outcomes when used prospectively in routine clinical practice. Nearly three-quarters of the studies in this review were performed in a US setting. Research is needed to understand the impact of variables such as poverty, urban/rural living, ethnicity and different rates of state/private/no medical insurance in other contexts.

\section{CONCLUSION}

It is possible with the information available in routine clinical practice to identify a child who is at increased risk of an acute attack. Many of the risk factors are potentially modifiable by parents acting to eliminate ETS or adhere to regular controller medication, by clinicians offering evidence-based treatment and self-management support, by healthcare systems ensuring equitable access to care and by policy initiatives addressing social deprivation and the public health challenges of smoking and obesity.

Acknowledgements We thank Marshall Dozier (Academic Support Librarian) for help with the search strategy, and Dr John Blakey for practical advice in the early stages.

Collaborators The ARC group members: Helen Benson; Steve Cunningham; Victoria Dalgliesh; Gwyneth Davies; Melissa Goodbourn; Susan Grieve; Jonathan Grigg; Hayley K Zislis; Erin McDonnell; Susan Morrow; Meagan Peterson; Daniel Russell; Jurgen Schwarze; San Selveindran; Nara Tagiyeva; Mike Thomas; Marissa Ware; Andrew Wilson.

Contributors HP led the development of the protocol, securing of funding, study administration, expert panel, workshop and writing of the paper. AS, SJ, AB, JH and MS contributed to the development of the protocol. SJ provided statistical advice. AudB and SMcL undertook the screening, data extraction and presentation of results. $H P, J Y P, J H, M S, A u d B$ and JFK formed the expert panel. All authors contributed to the interpretation of the findings. AudB wrote the initial draft of the paper with $\mathrm{SMCL}$ and HP, to which all the authors contributed. HP is the study guarantor.

Funding This research was supported by Asthma UK (Ref: AUK-SR-2015-01), with contributions from the Asthma UK Centre for Applied Research (AUK-AC-2012-01). AS is supported by the Farr Institute which is funded by a consortium of funders headed by the MRC.

Competing interests None declared.

Patient consent Not required.

Provenance and peer review Not commissioned; externally peer reviewed.

Data sharing statement All data are provided in the manuscript and online supplementary tables.

Open access This is an open access article distributed in accordance with the Creative Commons Attribution Non Commercial (CC BY-NC 4.0) license, which permits others to distribute, remix, adapt, build upon this work non-commercially, and license their derivative works on different terms, provided the original work is properly cited and the use is non-commercial. See: http://creativecommons.org/ licenses/by-nc/4.0/

(C) Article author(s) (or their employer(s) unless otherwise stated in the text of the article) 2018. All rights reserved. No commercial use is permitted unless otherwise expressly granted.

\section{REFERENCES}

1 Gibson GJ, Loddenkemper R, Sibille Y, et al. The European Lung White Book: Respiratory health and disease in Europe. Sheffield, UK: European Respiratory Society, 2013.

2 Mukherjee M, Stoddart A, Gupta RP, et al. The epidemiology, healthcare and societal burden and costs of asthma in the UK and its member nations: analyses of standalone and linked national databases. BMC Med 2016;14:113.

3 Bahadori K, Doyle-Waters MM, Marra C, et al. Economic burden of asthma: a systematic review. BMC Pulm Med 2009;9:24.

4 Royal College of Physicians. Why asthma still kills: the National Review of Asthma Deaths (NRAD) Confidential Enquiry report. London: RCP, 2014.

5 Bai TR, Vonk JM, Postma DS, et al. Severe exacerbations predict excess lung function decline in asthma. Eur Respir J 2007;30:452-6.

6 Global Initiative for Asthma. Global Strategy for Asthma Management and Prevention. 2017. http://www.ginasthma.org (accessed Aug 2017).

7 British Thoracic Society/Scottish Intercollegiate Guideline Network. British Guideline on the Management of Asthma. 2016. http://www.sign.ac.uk/sign-153-britishguideline-on-the-management-of-asthma.html (accessed Aug 2017).

8 Juniper EF, Gruffydd-Jones K, Ward S, et al. Asthma Control Questionnaire in children: validation, measurement properties, interpretation. Eur Respir J 2010;36:1410-6.

9 Liu AH, Zeiger R, Sorkness C, et al. Development and cross-sectional validation of the childhood asthma control test. J Allergy Clin Immunol 2007;119:817-25.

10 Pinnock H, Burton C, Campbell S, et al. Clinical implications of the Royal College of Physicians three questions in routine asthma care: a real-life validation study. Prim Care Respir J 2012;21:288-94.

11 Tagiveva N, McLean S, Sheikh A, et al. Protocol for a systematic review to identify and weight the indicators of risk of asthma exacerbations in children aged $5-12$ years. NPJ Prim Care Respir Med 2017;27:16088.

12 Higgins JPT, Green S. Cochrane Handbook for Systematic Reviews of Interventions Version 5.1.0. http://handbook.cochrane.org (accessed Aug 2017).

13 Moher D, Liberati A, Tetzlaff J, et al. Preferred reporting items for systematic reviews and meta-analyses: the PRISMA statement. PLoS Med 2009;6:e1000097.

14 Reddel HK, Taylor DR, Bateman ED, et al. on behalf of the ATS/ERS Task Force on Asthma Control and Exacerbations: An Official American Thoracic Society/European Respiratory Society statement: asthma control and exacerbations standardizing endpoints for clinical asthma trials and clinical practice. Am J Respir Crit Care Med 2009:180:59-99.

15 Wells GA, Shea B, O'Connell D, et al. The Newcastle-Ottawa Scale (NOS) for assessing the quality of non-randomised studies in meta-analyses. http://www.ohri.ca/programs/ clinical_epidemiology/oxford.asp (accessed Aug 2017).

16 Cochrane Effective Practice and Organisation of Care. EPOC resources for review authors. http://epoc.cochrane.org/resources/epoc-resources-review-authors (Accessed August 2017).

17 Greenhalgh T, Peacock R. Effectiveness and efficiency of search methods in systematic reviews of complex evidence: audit of primary sources. BMJ 2005;331:1064-5.

18 Baltrus P, Xu J, Immergluck L, et al. Individual and county level predictors of asthma related emergency department visits among children on Medicaid: a multilevel approach. J Asthma 2017:54:53-61.

19 Adams RJ, Fuhlbrigge A, Finkelstein JA, et al. Impact of inhaled antiinflammatory therapy on hospitalization and emergency department visits for children with asthma. Pediatrics 2001;107:706-11

20 Robroeks CM, van Vliet $D$, Jöbsis Q, et al. Prediction of asthma exacerbations in children: results of a one-year prospective study. Clin Exp Allergy 2012;42:792-8.

21 Black MH, Zhou H, Takayanagi M, et al. Increased asthma risk and asthma-related health care complications associated with childhood obesity. Am J Epidemiol 2013;178:1120-8 
22 Stewart KA, Higgins PC, McLaughlin CG, et al. Differences in prevalence, treatment, and outcomes of asthma among a diverse population of children with equal access to care: findings from a study in the military health system. Arch Pediatr Adolesc Med 2010;164:720-6.

23 Spahn J, Sheth K, Yeh WS, et al. Dispensing of fluticasone propionate/salmeterol combination in the summer and asthma-related outcomes in the fall. J Allergy Clin Immunol 2009;124:1197-203.

24 Andrews AL, Simpson AN, Basco WT, et al. Asthma medication ratio predicts emergency department visits and hospitalizations in children with asthma. Medicare Medicaid Res Rev 2013;3:E1-10.

25 Thomas M, Kocevar VS, Zhang Q, et al. Asthma-related health care resource use among asthmatic children with and without concomitant allergic rhinitis. Pediatrics 2005;115:129-34

26 Zhang T, Smith MA, Camp PG, et al. High use of health services in patients with suboptimal asthma drug regimens: a population-based assessment in British Columbia, Canada. Pharmacoepidemiol Drug Saf 2013;22:744-51.

27 Haselkorn T, Zeiger RS, Chipps BE, et al. Recent asthma exacerbations predict future exacerbations in children with severe or difficult-to-treat asthma. J Allergy Clin Immunol 2009:124:921-7.

28 Peters JI, McKinney JM, Smith B, et al. Impact of obesity in asthma: evidence from a large prospective disease management study. Ann Allergy Asthma Immunol 2011;106:30-5.

29 Engelkes M, Janssens HM, de Ridder MA, et al. Real life data on incidence and risk factors of severe asthma exacerbations in children in primary care. Respir Med 2016;119:48-54.

30 Schatz M, Zeiger RS, Zhang F, et al. Overweight/obesity and risk of seasonal asthma exacerbations. J Allergy Clin Immunol Pract 2013;1:618-22.

31 Farber HJ, Chi FW, Capra A, et al. Use of asthma medication dispensing patterns to predict risk of adverse health outcomes: a study of Medicaid-insured children in managed care programs. Ann Allergy Asthma Immunol 2004;92:319-28.

32 Brehm JM, Schuemann B, Fuhlbrigge AL, et al. Serum vitamin D levels and severe asthma exacerbations in the Childhood Asthma Management Program study. J Allergy Clin Immunol 2010;126:52-8

33 Pongracic JA, Visness CM, Gruchalla RS, et al. Effect of mouse allergen and rodent environmental intervention on asthma in inner-city children. Ann Allergy Asthma Immunol 2008;101:35-41.

34 Pongracic JA, O'Connor GT, Muilenberg ML, et al. Differential effects of outdoor versus indoor fungal spores on asthma morbidity in inner-city children. J Allergy Clin Immunol 2010:125:593-9.

35 Tolomeo C, Savrin C, Heinzer M, et al. Predictors of asthma-related pediatric emergency department visits and hospitalizations. J Asthma 2009;46:829-34

36 Schatz M, Cook EF, Joshua A, et al. Risk factors for asthma hospitalizations in a managed care organization: development of a clinical prediction rule. Am J Manag Care 2003:9:538-47.

37 Wu AC, Tantisira K, Li L, et al. Predictors of symptoms are different from predictors of severe exacerbations from asthma in children. Chest 2011;140:100-7.

38 Kwong KY, Morphew T, Scott L, et al. Asthma control and future asthmarelated morbidity in inner-city asthmatic children. Ann Allergy Asthma Immunol 2008;101:144-52

39 Murray MD, Stang P, Tierney WM. Health care use by inner-city patients with asthma. J Clin Epidemiol 1997;50:167-74.

40 McCormack MC, Aloe C, Curtin-Brosnan J, et al. Guideline-recommended fractional exhaled nitric oxide is a poor predictor of health-care use among inner-city children and adolescents receiving usual asthma care. Chest 2013:144:923-9.

41 Haselkorn T, Fish JE, Zeiger RS, et al. Consistently very poorly controlled asthma, as defined by the impairment domain of the Expert Panel Report 3 guidelines, increases risk for future severe asthma exacerbations in The Epidemiology and Natural History of Asthma: Outcomes and Treatment Regimens (TENOR) study. J Allergy Clin Immunol 2009;124:895-902.

42 Rabinovitch N, Reisdorph N, Silveira L, et al. Urinary leukotriene E4 levels identify children with tobacco smoke exposure at risk for asthma exacerbation. J Allergy Clin Immunol 2011:128:323-7.

43 Zeiger RS, Yegin A, Simons FE, et al. Evaluation of the National Heart, Lung, and Blood Institute guidelines impairment domain for classifying asthma control and predicting asthma exacerbations. Ann Allergy Asthma Immunol 2012;108:81-7.

44 Covar RA, Szefler SJ, Zeiger RS, et al. Factors associated with asthma exacerbations during a long-term clinical trial of controller medications in children. J Allergy Clin Immunol 2008:122:741-7.

45 Halterman JS, Yoos HL, Sidora K, et al. Medication use and health care contacts among symptomatic children with asthma. Ambul Pediatr 2001:1:275-9.

46 Torjusen EN, Diette GB, Breysse PN, et al. Dose-response relationships between mouse allergen exposure and asthma morbidity among urban children and adolescents. Indoor Air 2013;23:268-74

47 Visser CA, Brand PL. Does a single measurement of exhaled nitric oxide predict asthma exacerbations? Arch Dis Child 2011:96:781-2.

48 Vasbinder EC, Belitser SV, Souverein PC, et al. Non-adherence to inhaled corticosteroids and the risk of asthma exacerbations in children. Patient Prefer Adherence 2016;10:531-8.
49 Lieu TA, Quesenberry CP, Capra AM, et al. Outpatient management practices associated with reduced risk of pediatric asthma hospitalization and emergency department visits. Pediatrics 1997;100:334-41.

50 Blatter J, Brehm JM, Sordillo J, et al. Folate deficiency, atopy, and severe asthma exacerbations in Puerto Rican Children. Ann Am Thorac Soc 2016;13:223-32.

51 Pyle RC, Divekar R, May SM, et al. Asthma-associated comorbidities in children with and without secondhand smoke exposure. Ann Allergy Asthma Immunol 2015;115:205-10.

52 Quinto KB, Zuraw BL, Poon KY, et al. The association of obesity and asthma severity and control in children. J Allergy Clin Immunol 2011;128:964-9.

53 Rust G, Zhang S, Reynolds J. Inhaled corticosteroid adherence and emergency department utilization among Medicaid-enrolled children with asthma. J Asthma 2013:50:769-75.

54 Vernacchio L, Trudell EK, Muto JM. Correlation of care process measures with childhood asthma exacerbations. Pediatrics 2013;131:e136-43.

55 Rosas-Salazar C, Ramratnam SK, Brehm JM, et al. Parental numeracy and asthma exacerbations in Puerto Rican children. Chest 2013;144:92-8.

56 Brehm JM, Acosta-Pérez E, Klei L, et al. Vitamin D insufficiency and severe asthma exacerbations in Puerto Rican children. Am J Respir Crit Care Med 2012;186:140-6.

57 Pesek RD, Vargas PA, Halterman JS, et al. A comparison of asthma prevalence and morbidity between rural and urban schoolchildren in Arkansas. Ann Allergy Asthma Immunol 2010;104:125-31.

58 Lang JE, Hossain J, Smith K, et al. Asthma severity, exacerbation risk, and controller treatment burden in underweight and obese children. J Asthma 2012;49:456-63.

59 Bacharier LB, Dawson C, Bloomberg GR, et al. Hospitalization for asthma: atopic, pulmonary function, and psychological correlates among participants in the Childhood Asthma Management Program. Pediatrics 2003;112:e85-92.

60 McCarville M, Sohn MW, Oh E, et al. Environmental tobacco smoke and asthma exacerbations and severity: the difference between measured and reported exposure. Arch Dis Child 2013:98:510-4

61 Sarpong SB, Karrison T. Sensitization to indoor allergens and the risk for asthma hospitalization in children. Ann Allergy Asthma Immunol 1997;79:455-9.

62 Dales RE, Choi B, Chen Y, et al. Influence of family income on hospital visits for asthma among Canadian school children. Thorax 2002;57:513-7.

63 Findley S, Lawler K, Bindra M, et al. Elevated asthma and indoor environmental exposures among Puerto Rican children of East Harlem. J Asthma 2003;40:557-69.

64 Arabkhazaeli A, Vijverberg SJ, van Erp FC, et al. Characteristics and severity of asthma in children with and without atopic conditions: a cross-sectional study. BMC Pediatr 2015; 15:172.

65 Stingone JA, Claudio L. Asthma and enrollment in special education among urban schoolchildren. Am J Public Health 2006:96:1593-8.

66 Stingone JA, Claudio L. Disparities in the use of urgent health care services among asthmatic children. Ann Allergy Asthma Immunol 2006;97:244-50.

67 Mahut B, Beydon N, Delclaux C. Overweight is not a comorbidity factor during childhood asthma: the GrowthOb study. Eur Respir J 2012;39:1120-6.

68 Wiesenthal EN, Fagnano M, Cook S, et al. Asthma and overweight/obese: double trouble for urban children. J Asthma 2016;53:485-91.

69 Forno E, Fuhlbrigge A, Soto-Quirós ME, et al. Risk factors and predictive clinical scores for asthma exacerbations in childhood. Chest 2010;138:1156-65.

70 Friedlander JL, Sheehan WJ, Baxi SN, et al. Food allergy and increased asthma morbidity in a school-based inner-city asthma study. J Allergy Clin Immunol 2013;1:479-84.

71 Sunshine J, Song L, Krieger J. Written action plan use in inner-city children: is it independently associated with improved asthma outcomes? Ann Allergy Asthma Immunol 2011;107:207-13.

72 Castro-Rodriguez JA, Ramirez AM, Toche P, et al. Clinical, functional, and epidemiological differences between atopic and nonatopic asthmatic children from a tertiary care hospital in a developing country. Ann Allergy Asthma Immunol 2007:98:239-44.

73 Brown MS, Sarnat SE, DeMuth KA, et al. Residential proximity to a major roadway is associated with features of asthma control in children. PLoS One 2012:7:e37044.

74 Chilmonczyk BA, Salmun LM, Megathlin KN, et al. Association between exposure to environmental tobacco smoke and exacerbations of asthma in children. N Eng/ J Med 1993;328:1665-9.

75 Lasmar LMLBF, Camargos PAM, Ordones AB, et al. Prevalence of allergic rhinitis and its impact on the use of emergency care services in a group of children and adolescents with moderate to severe persistent asthma. J Pediatr 2007;83:555-61.

76 Rabito FA, Carlson J, Holt EW, et al. Cockroach exposure independent of sensitization status and association with hospitalizations for asthma in inner-city children. Ann Allergy Asthma Immunol 2011;106:103-9.

77 Akinbami LJ, Moorman JE, Garbe PL, et al. Status of childhood asthma in the United States, 1980-2007. Pediatrics 2009;123(Suppl3):S131-45.

78 Malhotra K, Baltrus P, Zhang S, et al. Geographic and racial variation in asthma prevalence and emergency department use among Medicaid-enrolled children in 14 southern states. J Asthma 2014;51:913-21.

79 Pinto Pereira LM, Jackman J, Figaro N, et al. Health burden of co-morbid asthma and allergic rhinitis in West Indian children. Allergol Immunopathol 2010;38:129-34.

80 Stingone JA, Ramirez OF, Svensson K, et al. Prevalence, demographics, and health outcomes of comorbid asthma and overweight in urban children. J Asthma 2011;48:876-85. 


\section{Asthma}

81 Quezada W, Kwak ES, Reibman J, et al. Predictors of asthma exacerbation among patients with poorly controlled asthma despite inhaled corticosteroid treatment. Ann Allergy Asthma Immunol 2016;116:112-7.

82 Wood PR, Smith LA, Romero D, et al. Relationships between welfare status, health insurance status, and health and medical care among children with asthma. Am J Public Health 2002;92:1446-52.

83 Searing DA, Zhang Y, Murphy JR, et al. Decreased serum vitamin D levels in children with asthma are associated with increased corticosteroid use. J Allergy Clin Immunol 2010;125:995-1000

84 Butz AM, Eggleston P, Huss K, et al. Nebulizer use in inner-city children with asthma: morbidity, medication use, and asthma management practices. Arch Pediatr Adolesc Med 2000;154:984-90.

85 Canino G, Garro A, Alvarez MM, et al. Factors associated with disparities in emergency department use among Latino children with asthma. Ann Allergy Asthma Immunol 2012;108:266-70.

86 National Committee for Quality Assurance. Use of appropriate medications for people with asthma and medication management for people with asthma. http://www.ncqa. org/report-cards/health-plans/state-of-health-care-quality/2016-table-of-contents/ asthma (accessed Jun 2017).
87 Puranik S, Forno E, Bush A, et al. Predicting severe asthma exacerbations in children. Am J Respir Crit Care Med 2017;195:854-9.

88 Pinnock $\mathrm{H}$, Fletcher $\mathrm{M}$, Holmes $\mathrm{S}$, et al. Setting the standard for routine asthma consultations: a discussion of the aims, process and outcomes of reviewing people with asthma in primary care. Prim Care Respir J 2010;19:75-83.

89 WONCA Europe. The European definition of General Practice and Family Medicine. 3rd Edn, 2011. (accessed Jun 2017).

90 Eaton S, Roberts S, Turner B. Delivering person centred care in long term conditions. BMJ 2015;350:h181.

91 Horne R, Chapman SC, Parham R, et al. Understanding patients' adherence-related beliefs about medicines prescribed for long-term conditions: a meta-analytic review of the Necessity-Concerns Framework. PLoS One 2013;8:e80633.

92 Pinnock H, Parke HL, Panagioti M, et al. Systematic meta-review of supported selfmanagement for asthma: a healthcare perspective. BMC Med 2017;15:64.

93 Mackay D, Haw S, Ayres JG, et al. Smoke-free legislation and hospitalizations for childhood asthma. N Engl J Med 2010;363:1139-45.

94 Riley RD, Hayden JA, Steyerberg EW, et al. Prognosis Research Strategy (PROGRESS) 2: prognostic factor research. PLoS Med 2013;10:e1001380. 